\title{
Osteosarcoma in patients below 25 years of age: An observational study of incidence, metastasis, treatment and outcomes
}

\author{
ZHIGANG NIE and HAO PENG \\ Department of Orthopedics, Renmin Hospital of Wuhan University, Wuhan, Hubei 430060, P.R. China
}

Received January 18, 2018; Accepted August 6, 2018

DOI: $10.3892 / \mathrm{ol} .2018 .9453$

\begin{abstract}
Only few systematic and comprehensive studies have focused on osteosarcoma in children and adolescents. In the present study, 3,085 patients with osteosarcoma were identified in the Surveillance, Epidemiology and End Results Program database. The patients were $<25$ years of age and diagnosed between 1973 to 2012. A retrospective study was performed to investigate the factors associated with tumor incidence, metastasis, treatment and survival. The results indicated that the incidence of osteosarcoma was higher in male patients compared with female patients. In addition, the incidence rate of osteosarcoma was higher among male and female patients between the ages of 10 and 19. Osteosarcoma located in the chest and pelvic bones was associated with metastatic disease; however, metastasis in two histological types, parosteal and periosteal, was infrequent. Survival analysis revealed the following were associated with poor outcomes: Sex, patients diagnosed between 1973 and 1982, distant metastasis, treatment without surgery or with radiation, a tumor with a poorly differentiated or undifferentiated grade, tumor size $\geq 100 \mathrm{~mm}$, and a tumor in the pelvic bones. Patient's whose histologic type was parosteal osteosarcoma and whose tumor was located in one of the limbs, or who underwent local or radical excision, exhibited a good survival outcome. Survival outcomes were ranked according to the type of surgery, from best to worst, as follows: Local excision, radical excision, amputation and no surgery. In summary, the incidence of osteosarcoma is higher in male patients compared with female patients. Furthermore, individuals between the ages of 10 and 19 have a higher risk of osteosarcoma. Osteosarcoma located in the chest and pelvic bones has a high risk of metastasis. Limb-salvage surgery may be the optimal treatment approach for non-metastatic osteosarcoma.
\end{abstract}

Correspondence to: Professor Hao Peng, Department of Orthopedics, Renmin Hospital of Wuhan University, 99 Zhangzhidong Road, Wuhan, Hubei 430060, P.R. China

E-mail: penghaowhu123@163.com

Key words: osteosarcoma, incidence, treatment, outcomes

\section{Introduction}

Osteosarcoma is frequently diagnosed in children and adolescents (1). Patients $<25$ years of age exhibit a higher incidence and constituent ratio compared with any other age group (2). Studies suggested patients $<25$ years of age with osteosarcoma constitute as a separate specific subgroup of the population $(3,4)$. Mirabello et al (2) reported that the epidemiologic features of osteosarcoma were unique among the $0-24 ; 25-59$ and $\geq 60$ years age groups, therefore emphasizing the need to study the aforementioned age groups separately. In the present study, osteosarcoma was examined in the younger age groups by conducting a systematic study of patients $<25$ years of age.

Single center and nationwide studies on osteosarcoma have been indicated to provide limited sample size $(5,6)$. The Surveillance, Epidemiology and End Results (SEER) program, which currently consists of 17 geographically defined registries and covers $\sim 26 \%$ of the U.S. population, is able to provide a large sample size. For osteosarcoma, the SEER program provides information regarding tumor site, histologic type, surgical type and incidence, which are useful parameters for clinical researchers. Therefore, the SEER program may assist clinicians with regard to early diagnosis and optimal treatment of the aforementioned tumor type.

Previous studies have primarily focused on all types of tumors, particularly bone tumors in $<25$ years of age (7-10) or osteosarcoma cases of all ages $(3,4,11)$. However, further systematic and comprehensive studies focusing on osteosarcoma in children and adolescents are required.

In the present study, the incidence based on year of diagnosis, age, sex, race, region, and metastasis was examined from different sites and histologic types. In addition, the study assessed the risk factors for survival outcomes from 15 factors, performed a pairwise comparison of these factors and elucidated optimal surgical options to provide additional knowledge regarding the characteristics of osteosarcoma in patients $<25$ years of age. The aim of the present cohort study was to identify useful factors for the prevention and treatment of osteosarcoma.

\section{Materials and methods}

Data source. All data were obtained from the SEER program (https://seer.cancer.gov/) and the SEER*Stat application 8.3.4 software (Surveillance Research Program, National Cancer 
Institute, Bethesda, MD, USA) was used for analysis. Patients between 0 and 24 years of age, who were diagnosed between 1973 and 2012 were selected for the present study. Histologic Type International Classification of Disease (ICD)-O-3 was input as 9180-9187 and 9192-9195, and Primary Site-Labeled was input as $\mathrm{C} 40.0-\mathrm{C} 41.9$ in the software to represent osteosarcoma. A total of 3,085 cases were available. Incidence, frequency and survival outcomes were analyzed according to the following 15 factors.

Study design. A total of 15 factors, including patientassociated factors, tumor-associated factors and treatment-associated factors, were included in the present study. Patient-associated factors consisted of year of diagnosis, sex, age at diagnosis, race, Contract Health Service Delivery Areas (CHSDA) region, and rural or urban. Tumor-associated factors included stage, grade, tumor size, laterality, Histologic Type ICD-O-3 and Primary Site-Labeled. Finally, treatment-associated factors consisted of surgery, surgery type and radiation.

The year of diagnosis was divided into the following 4 groups: 1973-1982; 1983-1992; 1993-2002; and 2003-2012. Age at diagnosis was divided as follows: 0-4 years; 5-9 years; 10-14 years; 15-19 years; and 20-24 years. Individuals were also categorized as Caucasian, African descent or other, which included American Indian/Alaska (AK) Native and Asian/Pacific Islander. CHSDA region was categorized as East, Northern Plains, Pacific Coast and Southwest. Rural or urban: Urban for patients in a metropolitan area and rural for patients not in a metropolitan area. Stage was divided into localized, regional and distant. Grade was divided into well-differentiated, moderately differentiated, poorly differentiated and undifferentiated. Tumor size was divided into the following groups: $<50 \mathrm{~mm} ; 50-99 \mathrm{~mm} ; 100-119 \mathrm{~mm}$; and $\geq 120 \mathrm{~mm}$. Laterality was divided into right and left, and surgery type was divided into no surgery, local excision, radical excision and amputation. Various histologic types, which had small samples in the univariate analysis, were excluded, while osteosarcoma, not otherwise specified, chondroblastic, fibroblastic, telangiectatic and parosteal were included. For Primary Site-Labeled the following were combined: C40.0 and C40.1, upper limbs; C40.2 and C40.3, lower limbs; C41.0 and C41.1, skull and mandible; C41.2 and C41.3, vertebral and chest bones; $\mathrm{C} 41.4$, pelvic bones.

Variables that had incomplete data among the 3,085 patients included surgery type, tumor size and grade. Cases for the present study were available through the SEER program, including 1,976 cases for surgery type recorded since 1998 , and 1,074 cases for tumor size recorded since 2004. Therefore, in the survival curve, the $\mathrm{x}$-axis for surgery type and tumor size did not correspond to 40 years. For tumor grade data, 1,834 cases were available in total, distributed throughout 1973-2012; however, there were numerous missing data.

Statistical analysis. The SEER*Stat application 8.3.4 software was used for statistical analysis of the data. Rate session was used to calculate incidence, and frequency session was used to calculate frequency. Incidence is indicated as the number per 1,000,000. Case listing session was used to collect the data of each patient and for further survival analysis. The
SPSS software 17.0 (SPSS, Inc., Chicago, IL, USA) was used to perform the survival analysis, log-rank testing, pairwise comparisons, five-year survival rate analysis, univariate analysis and multivariate Cox regression analysis. Associations among histological type, tumor site and stage were analyzed using $\chi^{2}$ tests. $\mathrm{P}<0.05$ was considered to indicate a statistically significant difference.

The aforementioned 15 factors were used to plot survival curves, and in log-rank testing, pairwise comparisons, five-year survival rate analysis and univariate analysis. A total of 3 factors, including grade, tumor size and surgery type, had incomplete data, and therefore, only 12 factors were included in the multivariate Cox regression analysis. Model 1 included all 12 factors, whereas Model 2 included 9 factors subsequent to excluding 3 factors, which exhibited no significant difference in the univariate analysis. The association between surgery type and survival was analyzed as a whole, but also for each stage and grade. The numbers of each case, the sequence of survival outcomes ranked from best to worst, and pairwise comparisons were calculated.

\section{Results}

Osteosarcoma incidence, age at diagnosis and survival for all age groups. As indicated in Fig. 1, the present study of osteosarcoma was performed in all age groups between 1973 and 2012. In the line chart two peaks for osteosarcoma incidence were indicated. The highest peak corresponded to the 0-24 age group, and the other peak corresponded to the $\geq 60$ age group (Fig. 1A). The majority of osteosarcoma cases were exhibited among patients between 10 and 14 years of age ( 7.6 per million) and between 15 and 19 years of age (8.2 per million) (Fig. 1A). As indicated in Fig. 1B the ratios of osteosarcoma were $56.8,27.6$ and $15.6 \%$ for $0-24,25-59$ and $\geq 60$ years of age, respectively. A survival curve indicated that for the three age groups, patients between 0 and 24 years of age had the best prognosis, while patients $\geq 60$ years of age had the worst prognosis $(\mathrm{P}<0.001$; Fig. 1C).

Incidence of osteosarcoma in patients $<25$ years of age. The incidence of osteosarcoma according to generation, sex, race, age group and CHSDA region are demonstrated in Table I. The overall incidence rate of osteosarcoma was 4.5 per million. The time span 1973-1982 had the lowest incidence rate, while the following 3 decades exhibited an increase in incidence rates compared with previous decades. However, differences among the 3 decades were not significant $(\mathrm{P}>0.05)$. Male patients had a higher incidence of osteosarcoma compared with female patients within each decade. The incidence rate in male patients with osteosarcoma increased between 1973 and 2003, and decreased between 2003 and 2012. Changes in female patients, according to generation, were not clear. Within each decade, races such as American Indian/Alaska Native and Asian/Pacific Islander, had the highest incidence rate, followed by patients of African descent and Caucasian. As time progressed, the incidence rate of osteosarcoma among Caucasian patients increased. However, the incidence rate of osteosarcoma decreased among other races, and remained unchanged among patients of African descent. No visible trend over time was observed for the 0-24-year-old group, but there 
Table I. Incidence of osteosarcoma in patients <25 years of age between 1973 and 2012 over 10-year intervals, according to sex, age at diagnosis, race and CHSDA region.

\begin{tabular}{|c|c|c|c|c|c|}
\hline Variables & $1973-1982$ & 1983-1992 & 1993-2002 & 2003-2012 & All \\
\hline \multicolumn{6}{|l|}{ Sex } \\
\hline Male & 4.2 & 5.2 & 5.6 & 5.2 & 5.1 \\
\hline Female & 3.8 & 4.0 & 3.9 & 4.0 & 3.9 \\
\hline \multicolumn{6}{|c|}{ Age at diagnosis (years) } \\
\hline $0-4$ & 0.5 & 0.5 & 0.3 & 0.4 & 0.4 \\
\hline $5-9$ & 1.5 & 2.9 & 2.7 & 2.7 & 2.5 \\
\hline $10-14$ & 7.3 & 7.3 & 7.9 & 7.7 & 7.6 \\
\hline $15-19$ & 7.4 & 8.6 & 8.8 & 7.9 & 8.2 \\
\hline $20-24$ & 3.0 & 3.6 & 4.0 & 4.1 & 3.7 \\
\hline \multicolumn{6}{|l|}{ Race } \\
\hline Caucasian & 3.7 & 4.4 & 4.6 & 4.5 & 4.3 \\
\hline African descent & 4.8 & 5.0 & 5.1 & 5.3 & 5.1 \\
\hline Other & 5.6 & 5.6 & 5.3 & 4.0 & 4.9 \\
\hline \multicolumn{6}{|l|}{ CHSDA region } \\
\hline East & 3.8 & 4.1 & 4.1 & 4.1 & 4.0 \\
\hline Northern plains & 3.7 & 4.5 & 5.1 & 5.4 & 4.6 \\
\hline Pacific coast & 4.3 & 5.0 & 4.5 & 4.4 & 4.6 \\
\hline Southwest & 4.1 & 4.9 & 5.6 & 4.6 & 4.8 \\
\hline All & 4.0 & 4.6 & 4.8 & 4.6 & 4.5 \\
\hline
\end{tabular}

CHSDA, Contract Health Service Delivery Areas.
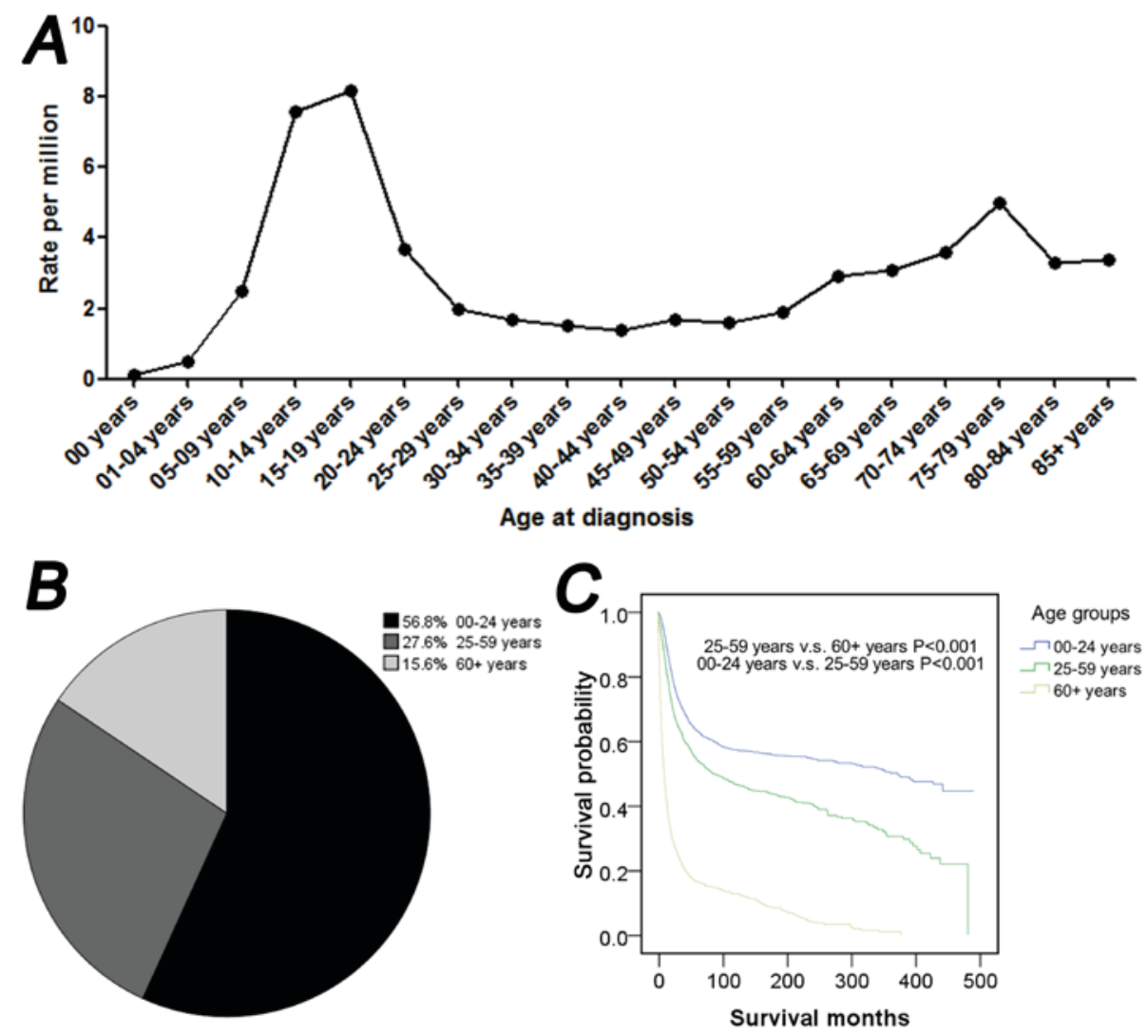

Figure 1. Osteosarcoma incidence, age distribution and survival, according to the age of diagnosis between 1973 and 2012. (A) Rate of osteosarcoma, according to the age of diagnosis. (B) Pie chart and (C) survival analysis curve of patients with osteosarcoma in the following age groups: 0-24; 25-59 and $\geq 60$ years of age. (C) Survival analysis curve in the following age groups: 0-24; 25-59 and $\geq 60$ years of age. 
Table II. Incidence of osteosarcoma in patients <25 years of age between 1973 and 2012, according to age group and sex

\begin{tabular}{|c|c|c|c|c|c|c|c|c|c|c|}
\hline \multirow[b]{2}{*}{ Age at diagnosis (years) } & \multicolumn{2}{|c|}{ 1973-1982 } & \multicolumn{2}{|c|}{ 1983-1992 } & \multicolumn{2}{|c|}{$1993-2002$} & \multicolumn{2}{|c|}{ 2003-2012 } & \multicolumn{2}{|c|}{ All } \\
\hline & Male & Female & Male & Female & Male & Female & Male & Female & Male & Female \\
\hline $0-4$ & 0.6 & 0.3 & 0.3 & 0.6 & 0.1 & 0.4 & 0.5 & 0.3 & 0.4 & 0.4 \\
\hline $5-9$ & 1.6 & 1.4 & 2.9 & 2.8 & 2.6 & 2.8 & 2.4 & 3.0 & 2.4 & 2.6 \\
\hline $10-14$ & 6.6 & 8.0 & 7.3 & 7.4 & 8.5 & 7.2 & 8.2 & 7.1 & 7.7 & 7.4 \\
\hline $15-19$ & 8.6 & 6.2 & 10.9 & 6.2 & 12.5 & 4.8 & 10.1 & 5.7 & 10.5 & 5.7 \\
\hline $20-24$ & 3.2 & 2.8 & 4.4 & 2.7 & 3.9 & 4.1 & 4.7 & 3.5 & 4.1 & 3.2 \\
\hline
\end{tabular}

were significant differences $(\mathrm{P}<0.05)$ within the age group, with the highest incidence rate indicated in patients between 10 and 19 years of age, followed by those of 20 and 24 years of age. No obvious findings for CHSDA regions were identified, except for the East region, which had the lowest incidence of osteosarcoma.

Incidence of osteosarcoma according to sex and age. Table II indicates the incidence rate of osteosarcoma in male and female patients in different age groups. It was demonstrated that female patients had a higher incidence rate of osteosarcoma compared with male patients, between 0-14 years of age, particularly between the ages of 0-4, 5-9 and 10-14 diagnosed between 1983 and 2002, 1993 and 2012, and 1973 and 1992, respectively. When combining the 4 decades, 1973-1982, 1983-1992, 1993-2002 and 2003-2012, female patients had a higher incidence at 5-9 years of age (Table II).

Association among histologic type, tumor site and metastasis. Table III indicated the association between histologic type and site with risk of metastatic disease. The 'distant' stage was defined as metastasis. The results of the present study indicated that the chest and pelvic bones had a higher prevalence rate of metastatic disease, while the long bone of the upper limbs had a higher prevalence rate of metastatic disease compared with the lower limbs. Parosteal and periosteal osteosarcoma were two histologic types with a low risk of metastasis.

The five-year survival rate, univariate analysis and pairwise comparisons. Table IV summarized the five-year survival rates and univariate analyses for 15 factors. Survival curves and the results of pairwise comparisons are presented in Fig. 2 for patient-associated factors and Fig. 3 for tumor-associated factors and treatment-associated factors. Survival outcome was worst between 1973-1982, and the following 3 decades exhibited an improved survival outcome. When each of the 3 decades was compared with 1973-1982, all results exhibited significant differences $(\mathrm{P}<0.05)$, but comparisons within the 3 decades indicated no differences $(\mathrm{P}>0.05)$. Female patients had relatively good survival outcomes compared with male patients $(\mathrm{P}<0.001)$. The survival outcome from best to worst among the different age groups was as follows: $10-14 ;>5-9 ;>20-24 ;>15-19$ and $>0-4$ years of age, but there were no significant differences in pairwise comparisons among the groups $(\mathrm{P}>0.05)$.

There were no significant differences among races $(\mathrm{P}>0.05)$. In addition, no significant differences were observed among
CHSDA regions $(\mathrm{P}>0.05)$, except that the region with the best outcome, East, was significantly different compared with the region with the worst outcome, Southwest $(\mathrm{P}<0.05)$. Patients from rural and urban areas had no significant difference in survival outcome $(\mathrm{P}>0.05)$. There were significant differences in stage according to pairwise comparisons and the entire comparison $(\mathrm{P}<0.001)$. Well- and moderately differentiated subtypes of grade corresponded to relatively good survival outcomes compared with the poorly differentiated and undifferentiated subtypes $(\mathrm{P}<0.05)$, but no significant differences were demonstrated within well- and moderately differentiated or within poorly differentiated and undifferentiated subtypes $(\mathrm{P}>0.05)$. The survival curve indicated that a large tumor size was associated with relatively poor survival outcomes, and there was a significant difference in survival outcome between patients with a tumor size $<50 \mathrm{~mm}$ and patients with a tumor size $>100 \mathrm{~mm}(\mathrm{P}<0.05)$. There was no significant difference between tumors located on the left and right lateral $(\mathrm{P}>0.05)$. Parosteal osteosarcoma had the best survival outcome with a five-year survival rate of $89.0 \%$ and was significantly different from all other histological types of osteosarcoma $(\mathrm{P}<0.001)$. The tumor sites ranked from best to worst survival outcome were as follows: Skull and mandible; lower limb; upper limb; vertebral and chest bones, and pelvic bones. In pairwise comparisons, there were significant differences between chest bones and pelvic bones $(\mathrm{P}=0.001)$ and between lower limbs and upper limbs $(\mathrm{P}<0.001)$. Patients who underwent surgery had relatively good survival outcomes compared with those who did not $(\mathrm{P}<0.001)$. The surgery types, which were ranked from best to worst for survival outcome were local excision, radical excision, amputation and no surgery. There was no significant difference between local excision and radical excision, according to pairwise comparisons $(\mathrm{P}>0.05)$, however, all other types of surgery were associated with significant differences $(\mathrm{P}<0.001)$. Patients who underwent radiation had relatively poor survival outcomes compared with patients who did not receive radiation $(\mathrm{P}<0.001)$.

Association between surgery type and survival outcome. As the association between surgery type and survival outcome may be confounded by other factors, including stage and grade of osteosarcoma, survival curves were plotted and log-rank tests were performed for the same stage or grade (Table V). The frequency of amputation as a treatment for osteosarcoma was higher among patients with 'localized' stage of osteosarcoma, while patients with 'distant' stage of osteosarcoma 
Table III. Association among histologic type, tumor site and stage in patients <25 years of age with osteosarcoma between 1973 and 2012 .

\begin{tabular}{|c|c|c|c|c|}
\hline Variables & Localized, n (\%) & Regional, n (\%) & Distant, n (\%) & P-value \\
\hline Histologic type ICD-O-3 & & & & ${ }^{\mathrm{a}} \mathrm{P}<0.001$ \\
\hline Osteosarcoma, NOS & $724(35.0)$ & $905(43.8)$ & $438(21.2)$ & \\
\hline Chondroblastic osteosarcoma & $117(29.7)$ & $208(52.8)$ & $69(17.5)$ & \\
\hline Fibroblastic osteosarcoma & $42(35.9)$ & $56(47.9)$ & $19(16.2)$ & \\
\hline Telangiectatic osteosarcoma & $39(36.4)$ & $52(48.6)$ & $16(15.0)$ & \\
\hline Osteosarcoma in Paget disease of bone & $1(100.0)$ & $0(0.0)$ & $0(0.0)$ & \\
\hline Small cell osteosarcoma & $9(39.1)$ & $10(43.5)$ & $4(17.4)$ & \\
\hline Central osteosarcoma & $16(32.0)$ & $28(56.0)$ & $6(12.0)$ & \\
\hline Intraosseous well-differentiated osteosarcoma & $1(50.0)$ & $1(50.0)$ & $0(0.0)$ & \\
\hline Parosteal osteosarcoma & $69(65.7)$ & $31(29.5)$ & $5(4.8)$ & \\
\hline Periosteal osteosarcoma & $16(57.1)$ & $10(35.7)$ & $2(7.1)$ & \\
\hline High-grade surface osteosarcoma & $1(12.5)$ & $4(50.0)$ & $3(37.5)$ & \\
\hline Primary site-labeled & & & & ${ }^{\mathrm{a}} \mathrm{P}<0.001$ \\
\hline C40.0-Long bones: Upper limb, scapula, and associated joints & $118(34.3)$ & $149(43.3)$ & $77(22.4)$ & \\
\hline C40.1-Short bones of upper limb and associated joints & $5(50.0)$ & $5(50.0)$ & $0(0.0)$ & \\
\hline C40.2-Long bones of lower limb and associated joints & $796(36.8)$ & $973(45.0)$ & $394(18.2)$ & \\
\hline C40.3-Short bones of lower limb and associated joints & $13(36.1)$ & $17(47.2)$ & $6(16.7)$ & \\
\hline C41.0-Bones of skull and face and associated joints & $32(36.8)$ & $39(44.8)$ & $16(18.4)$ & \\
\hline C41.1 Mandible & $23(39.7)$ & $30(51.7)$ & $5(8.6)$ & \\
\hline C41.2 Vertebral column & $13(41.9)$ & $13(41.9)$ & $5(16.1)$ & \\
\hline C41.3 Rib, Sternum, Clavicle and associated joints & $12(27.3)$ & $18(40.9)$ & $14(31.8)$ & \\
\hline C41.4-Pelvic bones, sacrum, coccyx and associated joints & $22(17.9)$ & $59(48.0)$ & $42(34.1)$ & \\
\hline C41.9-Bone, NOS & $1(16.7)$ & $2(33.3)$ & $3(50.0)$ & \\
\hline
\end{tabular}

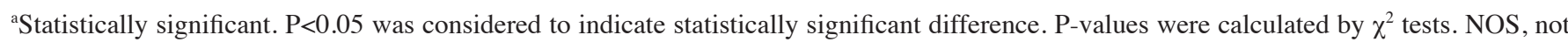
otherwise specified; n, number; ICD, International Classification of Disease.

were not surgically treated. In addition, amputation was indicated to be higher among patients with 'undifferentiated' grade of osteosarcoma. In the comparison of surgery types among patients with the same stage or grade of osteosarcoma, results of survival outcome based on surgery type were almost identical. The results of the present study indicated that for types of surgery the best to worst survival outcomes were as follows: Local excision, radical excision, amputation and no surgery. The aforementioned result was also indicated for the total number of patients. Therefore, local excision may be the optimal choice for patients with any type of osteosarcoma, conflicting with the previous notion that amputation is the optimal choice of treatment. In addition, as indicated in the results of Table $\mathrm{V}$, radical excision may be an optimal choice for patients with metastatic disease.

Multivariate Cox regression analysis. In the univariate analysis, factors with significant differences included year of diagnosis, sex, age at diagnosis, CHSDA region, stage, grade, tumor size, histologic type, tumor site, surgery, surgery type and radiation $(\mathrm{P}<0.05)$. The results of the multivariate Cox regression analysis are indicated in Table VI. Year of diagnosis, sex, age at diagnosis, CHSDA region, stage, histologic type, tumor site, surgery and radiation were independent risk factors in Model 1 of the multivariate Cox regression analysis $(\mathrm{P}<0.05)$. In Model 2 of the multivariate Cox regression analysis, independent risk factors included year of diagnosis, sex, CHSDA region, stage, histologic type, tumor site, surgery and radiation $(\mathrm{P}<0.05)$.

\section{Discussion}

At the start of the present study, the distribution characteristics for the incidence of osteosarcoma was indicated according to age. The results demonstrated that patients $<25$ years of age with osteosarcoma had relatively good survival outcomes, but also had the highest ratio $(56.8 \%)$ and incidence $(8.2$ per million) among all age groups. The aforementioned result may be due to certain characteristics of this age group, which remain unknown. Therefore, this specific age group requires further study in terms of incidence, metastasis, survival prognosis and treatment options for osteosarcoma, according to the aforementioned 15 factors.

The lowest incidence rate of osteosarcoma and worst survival outcomes were observed between 1973 and 1982, while the subsequent 3 decades had the highest incidence rate and best outcomes. Within these 3 decades, incidences and survival outcomes minimally changed. The five-year survival 
Table IV. Five-year survival rate and univariate analysis in patients with osteosarcoma <25 years of age between 1973 and 2012.

\begin{tabular}{|c|c|c|c|c|}
\hline \multirow[b]{2}{*}{ Variables } & \multirow[b]{2}{*}{$\mathrm{n}(\%)$} & \multirow[b]{2}{*}{ Survival (95\% CI) } & \multicolumn{2}{|c|}{ Univariate analysis } \\
\hline & & & $\mathrm{HR}(95 \% \mathrm{CI})$ & P-value \\
\hline Year of diagnosis & & & & ${ }^{\mathrm{a}} \mathrm{P}<0.001$ \\
\hline 1973-1982 & 357 (11.6) & $50.1(45.0-55.2)$ & Reference & \\
\hline 1983-1992 & $404(13.1)$ & $62.7(58.0-67.4)$ & $0.701(0.576-0.852)$ & ${ }^{\mathrm{a}} \mathrm{P}<0.001$ \\
\hline 1993-2002 & $851(27.6)$ & $63.5(60.2-66.8)$ & $0.661(0.557-0.784)$ & ${ }^{\mathrm{a}} \mathrm{P}<0.001$ \\
\hline 2003-2012 & $1,473(47.7)$ & $66.3(63.6-69.0)$ & $0.582(0.493-0.687)$ & ${ }^{\text {a }} \mathrm{P}<0.001$ \\
\hline Sex & & & & ${ }^{\mathrm{a}} \mathrm{P}<0.001$ \\
\hline Male & $1,757(57.0)$ & $60.1(57.7-62.5)$ & Reference & \\
\hline Female & $1,328(43.0)$ & $67.3(64.8-69.8)$ & $0.757(0.675-0.849)$ & ${ }^{\mathrm{a}} \mathrm{P}<0.001$ \\
\hline Age at diagnosis (years) & & & & ${ }^{\mathrm{a}} 0.014$ \\
\hline $0-4$ & 49 (1.6) & $54.1(39.2-69.0)$ & Reference & \\
\hline $5-9$ & $368(11.9)$ & $64.2(59.1-69.3)$ & $0.728(0.468-1.131)$ & 0.158 \\
\hline $10-14$ & $1,064(34.5)$ & $66.4(63.5-69.3)$ & $0.666(0.437-1.014)$ & 0.058 \\
\hline $15-19$ & $1,102(35.7)$ & $60.0(57.1-62.9)$ & $0.828(0.545-1.258)$ & 0.376 \\
\hline $20-24$ & $502(16.3)$ & $63.8(59.5-68.1)$ & $0.776(0.504-1.194)$ & 0.249 \\
\hline Race & & & & 0.939 \\
\hline Caucasian & $2,289(74.2)$ & $63.2(61.0-65.4)$ & Reference & \\
\hline African descent & $476(15.4)$ & $62.1(57.6-66.6)$ & $1.023(0.877-1.194)$ & 0.771 \\
\hline Other & $296(9.6)$ & $62.6(56.9-68.3)$ & 0.985 (0.814-1.191) & 0.872 \\
\hline CHSDA region & & & & ${ }^{\mathrm{a}} 0.011$ \\
\hline East & $843(27.3)$ & $65.8(62.5-69.1)$ & Reference & \\
\hline Northern Plains & $479(15.5)$ & $61.8(57.3-66.3)$ & $1.169(0.981-1.394)$ & 0.081 \\
\hline Pacific Coast & $1,465(47.5)$ & $63.4(60.9-65.9)$ & $1.114(0.970-1.280)$ & 0.127 \\
\hline Southwest & $295(9.6)$ & $56.5(50.6-62.4)$ & $1.394(1.142-1.701)$ & ${ }^{\mathrm{a}} 0.001$ \\
\hline Rural or urban & & & & 0.098 \\
\hline Rural & $264(8.6)$ & $60.8(54.7-66.9)$ & Reference & \\
\hline Urban & $2,758(89.4)$ & $63.5(61.5-65.5)$ & $0.852(0.704-1.031)$ & 0.098 \\
\hline Stage & & & & ${ }^{\mathrm{a}} \mathrm{P}<0.001$ \\
\hline Localized & $1,034(33.5)$ & $77.5(74.8-80.2)$ & Reference & \\
\hline Regional & $1,305(42.3)$ & $64.7(62.0-67.4)$ & $1.640(1.416-1.900)$ & ${ }^{\text {a }} \mathrm{P}<0.001$ \\
\hline Distant & $562(18.2)$ & $31.1(27.0-35.2)$ & $4.442(3.798-5.196)$ & ${ }^{\mathrm{a}} \mathrm{P}<0.001$ \\
\hline Grade & & & & ${ }^{\mathrm{a}} \mathrm{P}<0.001$ \\
\hline Well & $86(2.8)$ & $81.1(72.5-89.7)$ & Reference & \\
\hline Moderately & $125(4.1)$ & $78.0(70.4-85.6)$ & $1.142(0.653-1.997)$ & 0.641 \\
\hline Poorly & $524(17.0)$ & $61.4(56.9-65.9)$ & $2.073(1.307-3.287)$ & ${ }^{\mathrm{a}} 0.002$ \\
\hline Undifferentiated & $1,100(35.7)$ & $64.5(61.6-67.4)$ & $2.015(1.286-3.163)$ & ${ }^{\mathrm{a}} 0.002$ \\
\hline Tumor size (mm) & & & & ${ }^{\mathrm{a}} \mathrm{P}<0.001$ \\
\hline$<50$ & $127(4.1)$ & $79.5(71.7-87.3)$ & Reference & \\
\hline $50-99$ & $458(14.8)$ & $73.2(68.7-77.7)$ & $1.250(0.809-1.930)$ & 0.315 \\
\hline $100-119$ & $149(4.8)$ & $64.3(55.9-72.7)$ & $1.751(1.082-2.836)$ & ${ }^{\mathrm{a}} 0.023$ \\
\hline$\geq 120$ & $340(11.0)$ & $56.4(49.9-62.9)$ & $2.119(1.376-3.263)$ & ${ }^{\mathrm{a}} 0.001$ \\
\hline Laterality & & & & 0.371 \\
\hline Right & $1,364(44.2)$ & $50.0(47.5-52.5)$ & Reference & \\
\hline Left & $1,367(44.3)$ & $63.3(60.6-66.0)$ & $1.056(0.937-1.191)$ & 0.371 \\
\hline Histologic Type ICD-O-3 & & & & ${ }^{\mathrm{a}} \mathrm{P}<0.001$ \\
\hline Osteosarcoma, NOS & $2,223(72.1)$ & $60.8(58.6-63.0)$ & Reference & \\
\hline Chondroblastic & 407 (13.2) & $62.4(57.5-67.3)$ & $0.912(0.770-1.080)$ & 0.286 \\
\hline Fibroblastic & $122(4.0)$ & $69.9(61.7-78.1)$ & $0.732(0.539-0.994)$ & ${ }^{\mathrm{a}} 0.045$ \\
\hline Telangiectatic & $109(3.5)$ & $70.2(61.0-79.4)$ & $0.774(0.557-1.075)$ & 0.127 \\
\hline Parosteal & $111(3.6)$ & $89.0(82.9-95.1)$ & $0.287(0.180-0.457)$ & ${ }^{\text {a } P}<0.001$ \\
\hline
\end{tabular}


Table IV. Continued.

Univariate analysis

\begin{tabular}{|c|c|c|c|c|}
\hline Variables & $\mathrm{n}(\%)$ & Survival $(95 \% \mathrm{CI})$ & HR $(95 \% \mathrm{CI})$ & P-value \\
\hline Primary site-labeled & & & & ${ }^{\mathrm{a}} \mathrm{P}<0.001$ \\
\hline Upper limb & $378(12.3)$ & $56.8(51.5-62.1)$ & Reference & \\
\hline Lower limb & $2,321(75.2)$ & $66.4(64.4-68.3)$ & $0.737(0.627-0.867)$ & ${ }^{\mathrm{a}} \mathrm{P}<0.001$ \\
\hline Skull and mandible & $155(5.0)$ & $67.6(60.0-75.2)$ & $0.694(0.511-0.944)$ & ${ }^{\mathrm{a}} 0.02$ \\
\hline Vertebral and chest bones & $79(2.6)$ & $48.2(37.0-59.4)$ & $1.301(0.943-1.795)$ & 0.109 \\
\hline Pelvic bones & $135(4.4)$ & $31.1(22.9-39.3)$ & $2.339(1.827-2.993)$ & ${ }^{\mathrm{a}} \mathrm{P}<0.001$ \\
\hline Surgery & & & & ${ }^{\mathrm{a}} \mathrm{P}<0.001$ \\
\hline Yes & $2,613(84.7)$ & $66.3(64.3-68.3)$ & Reference & \\
\hline No & 399 (12.9) & $44.6(39.5-49.7)$ & $2.113(1.831-2.438)$ & ${ }^{\mathrm{a}} \mathrm{P}<0.001$ \\
\hline Surgery type & & & & ${ }^{\mathrm{a}} \mathrm{P}<0.001$ \\
\hline No surgery & $244(7.9)$ & $42.4(35.9-48.9)$ & Reference & \\
\hline Local excision & $208(6.7)$ & $75.3(69.2-81.4)$ & $0.310(0.226-0.426)$ & ${ }^{\mathrm{a}} \mathrm{P}<0.001$ \\
\hline Radical excision & $1,076(34.9)$ & $71.1(68.2-74.0)$ & $0.344(0.281-0.422)$ & ${ }^{\mathrm{a}} \mathrm{P}<0.001$ \\
\hline Amputation & 389 (12.6) & $61.7(56.6-66.8)$ & $0.494(0.391-0.624)$ & ${ }^{\mathrm{a}} \mathrm{P}<0.001$ \\
\hline Radiation & & & & ${ }^{\mathrm{a}} \mathrm{P}<0.001$ \\
\hline Yes & $163(5.3)$ & $35.3(27.7-42.9)$ & Reference & \\
\hline No & 2,881 (93.4) & $64.8(63.0-66.6)$ & $0.373(0.308-0.450)$ & ${ }^{\mathrm{a}} \mathrm{P}<0.001$ \\
\hline
\end{tabular}

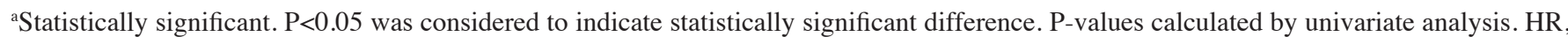
hazard ratio; CI, confidence interval; n, number; ICD, International Classification of Disease; NOS, not otherwise specified; CHSDA, Contract Health Service Delivery Areas.

rate was $50.1 \%$ prior to 1982 and $>60 \%$ subsequent to this year. The increased incidence of osteosarcoma, following 1982, may be due to the diagnostic improvements for osteosarcoma. Numerous studies have also observed that there was improvement in survival for patients diagnosed with osteosarcoma subsequent to 1982 , which according to the studies may be due to the introduction of chemotherapeutic regimens $(12,13)$. Duffaud et al (14) reported that localized high-grade osteosarcoma had a long-term disease-free survival rate of $<20 \%$ prior to the administration of intensive chemotherapy and $55-75 \%$ subsequent to the introduction of the aforementioned treatment. The patient-derived orthotopic xenograft model, developed over the past 30 years, is a promising research method for effective individualized therapy, which has been applied to various types of cancer, including breast, ovarian, lung, cervical, colon, stomach, pancreatic, melanoma, sarcoma, and osteosarcoma (15). Using the aforementioned model, Murakami et al (16) and Igarashi et al (17) indicated that the tumor-targeting Salmonella typhimurium A1-R is a powerful treatment option and they reported that it was able to regress osteosarcoma. The authors of the aforementioned studies also used this model to screen drugs and identify effective treatment drugs or drug combinations for osteosarcoma $(18,19)$.

Sex-associated differences revealed that male patients had a higher incidence rate of osteosarcoma compared with female patients, which was consistent even within the same race and region (data not shown). The only exception was that female patients 5-9 years of age had a higher incidence rate of osteosarcoma compared with male patients. The aforementioned results may be due to the active bone growth reported in males and females (20). It has been reported that males undergo more rapid bone growth compared with females (21). However, females between the ages of 11 and 13 have been reported to be taller and undergo rapid bone growth compared with age-matched males (22). Numerous studies have reported that as the height of an individual increases so does the risk of osteosarcoma (20,23-25). A higher incidence rate of osteosarcoma was additionally observed in female patients between 0 and 14 years of age in a study by Mirabello et al (2) and in female patients between 10 and 14 years of age in a study by Homa et al (26). Regarding sex-associated differences in survival, numerous studies $(27,28)$ have reported that females have a longer life span compared with males; results which confirm the present study's findings. Researchers have attributed the aforementioned survival difference to the relatively poor response reported in male patients to chemotherapy, and their high recurrence rate $(29,30)$. In the present study it was additionally proposed that males may exhibit symptoms in the long-term and therefore, do not participate actively in treatment.

Regarding age, the highest incidence of osteosarcoma was among those 10-19 years of age, followed by those between 20 and 24 years of age, which may be due to the rapid bone growth of the aforementioned age groups. The optimal survival rate was observed in patients between 10 and 14 years of age and between 5 and 9 years of age, whereas the worst survival rate was observed in patients between 1 and 4 years of age. The survival results of the present study were verified by 
Table V. Association between surgery type and survival outcome in patients <25 years of age with osteosarcoma between 1973 and 2012, according to stage and grade.

Stage $(\mathrm{n}=1,915)$

Grade $(n=1,439)$

Variables

Localized Regional Distant Well Moderately Poorly Undifferentiated $(\mathrm{n}=1977)$

Number

No surgery

Local excision

Radical excision

Amputation

(2)

Order of outcome

Best

Relatively poor

Worst

Significance

\begin{tabular}{lcccccccc} 
No surgery vs. local excision & ${ }^{a} 0.031$ & ${ }^{\mathrm{a}} \mathrm{P}<0.001$ & ${ }^{\mathrm{a}} 0.011$ & 0.622 & 0.523 & ${ }^{\mathrm{a}} 0.005$ & ${ }^{a} \mathrm{P}<0.001$ & ${ }^{\mathrm{a}} \mathrm{P}<0.001$ \\
No surgery vs. radical excision & ${ }^{\mathrm{a}} 0.046$ & ${ }^{\mathrm{a}} \mathrm{P}<0.001$ & ${ }^{\mathrm{a}} \mathrm{P}<0.001$ & 0.724 & 0.113 & ${ }^{\mathrm{a}} \mathrm{P}<0.001$ & ${ }^{\mathrm{a}} \mathrm{P}<0.001$ & ${ }^{\mathrm{a}} \mathrm{P}<0.001$ \\
No surgery vs. amputation & 0.478 & ${ }^{\mathrm{a}} \mathrm{P}<0.001$ & ${ }^{\mathrm{a}} 0.001$ & 0.385 & 0.994 & ${ }^{\mathrm{a}} 0.033$ & ${ }^{a} \mathrm{P}<0.001$ & ${ }^{\mathrm{a}} \mathrm{P}<0.001$ \\
Local excision vs. radical excision & 0.469 & 0.557 & 0.202 & 0.505 & 0.393 & 0.682 & 0.576 & 0.462 \\
Local excision vs. amputation & 0.092 & 0.243 & 0.589 & ${ }^{\mathrm{a}} 0.037$ & 0.358 & 0.165 & 0.087 & ${ }^{a} 0.001$ \\
Radical excision vs. amputation & 0.139 & 0.263 & ${ }^{\mathrm{a}} 0.002$ & ${ }^{\mathrm{a}} 0.006$ & ${ }^{\mathrm{a}} 0.014$ & 0.081 & ${ }^{\mathrm{a}} 0.042$ & ${ }^{\mathrm{a}} \mathrm{P}<0.001$ \\
\hline
\end{tabular}

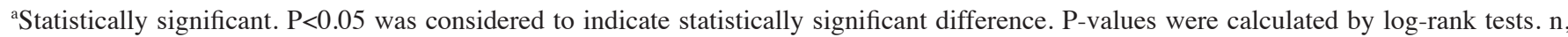
number.
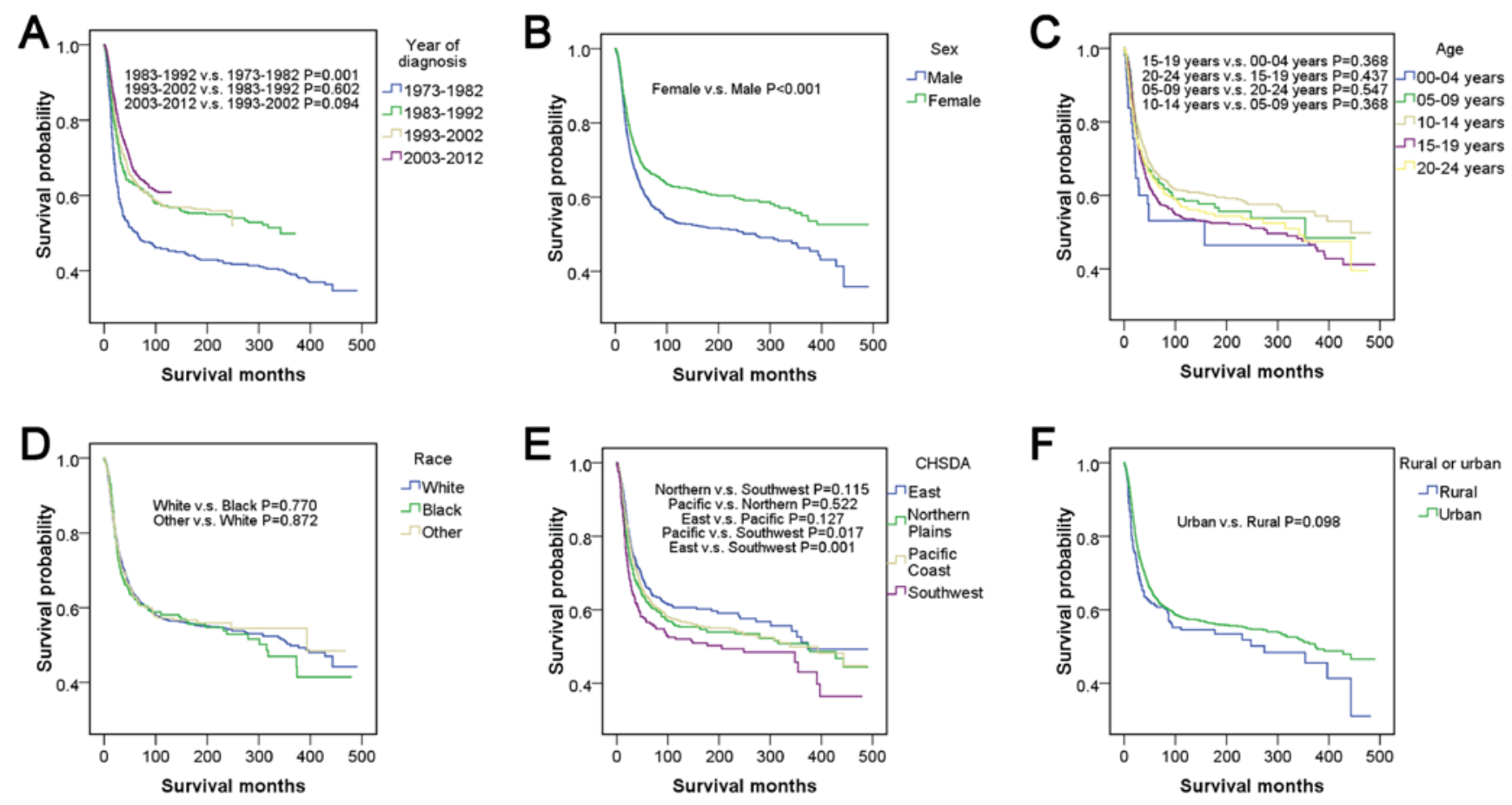

Figure 2. Survival analyses, according to (A) year of diagnosis, (B) sex, (C) age, (D) race, (E) CHSDA region and (F) rural or urban in patients $<25$ years of age with osteosarcoma between 1973 and 2012. CHSDA, Contract Health Service Delivery Areas.

other single-center studies (31-33). Guillon et al (31) analyzed 15 patients $<5$ years of age with osteosarcoma and reported a mortality rate of $45 \%$ (7 patients) within 5 years of follow-up, suggesting that osteosarcoma is highly invasive in patients 

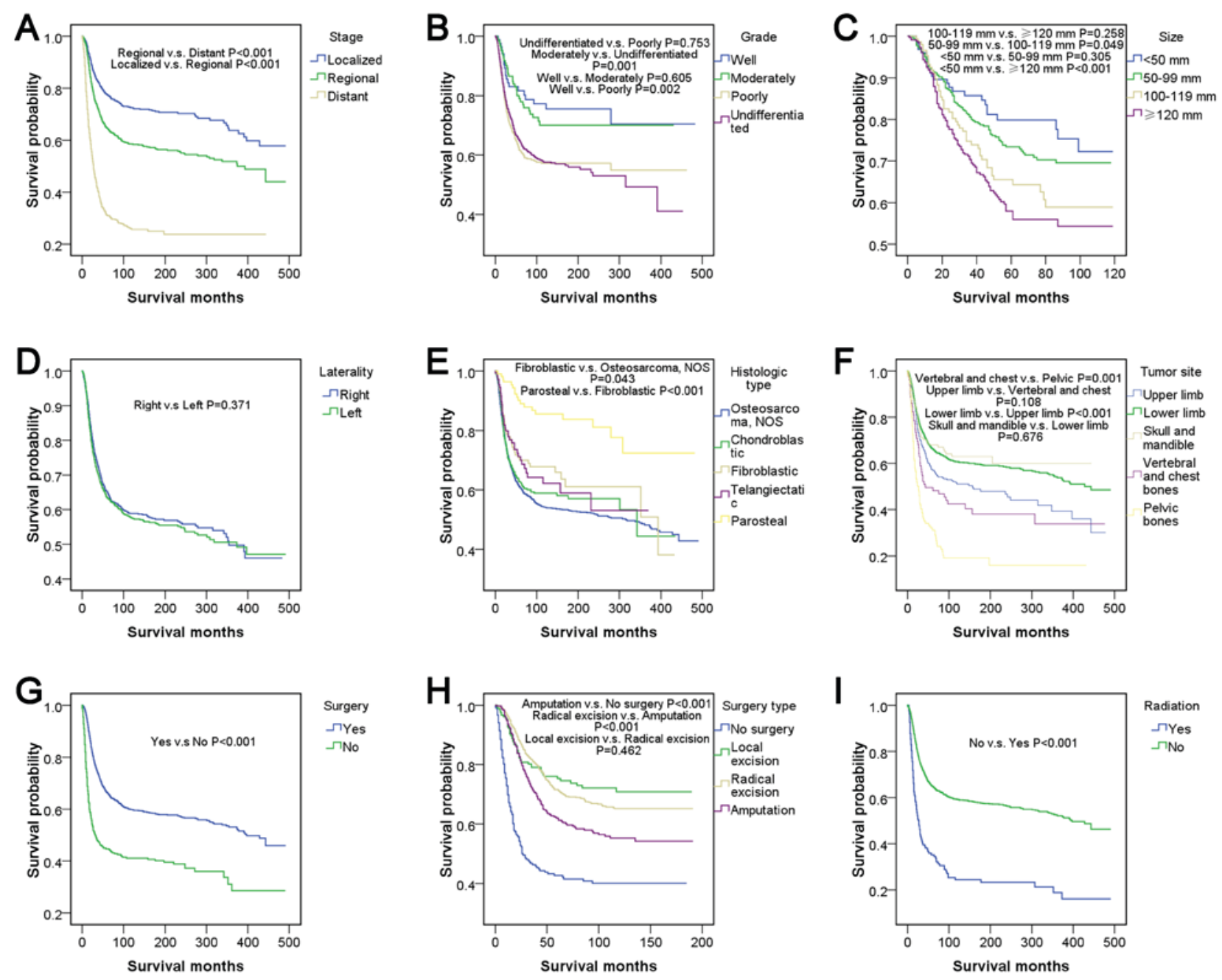

Figure 3. Survival analyses, according to (A) stage, (B) grade, (C) tumor size, (D) laterality, (E) histologic type, (F) tumor site, (G) surgery, (H) surgery type and (I) radiation in patients <25 years of age with osteosarcoma between 1973 and 2012. NOS, not otherwise specified.

$<5$ years of age. Worch et al (32) reported that the five-year survival rate of children $\leq 5$ years of age and $>5$ years of age was 51.9 and $67.3 \%$, respectively. Sugalski et al (33) reported that the five-year survival rate of children $<12$ years of age and $>12$ years of age was 11 and $57 \%$, respectively. However, Hagleitner et al (34) reported an opposite trend, where the 5 -year overall survival rate was $70.6 \pm 0.8,52.5 \pm 1.1,33.3 \pm 0.9 \%$ in patients $\leq 14,15-19$ and 20-40 years of age, respectively. The reason for the decrease in survival rate in young patients remains unclear, however, the aforementioned findings suggest that tumors in patients with different ages have different biological characteristics. Furthermore, limb salvage surgery poses surgical challenges for skeletally immature patients, as it may cause leg-length inequality in the long-term (35). It has been reported that patients $<5$ years of age undergo amputation at a higher rate, whereas only a number of patients receive chemotherapy (32).

Miller et al (36) defined patients at the stage of 'distant' in the SEER database as metastatic, whereas patients at the stage of 'localized' or 'regional' were defined as non-metastatic. Miller et al (36), including other researchers, have reported that patients with metastatic osteosarcoma had a relatively poor prognosis compared with patients with localized osteosarcoma $(37,38)$. The present study compared the aforementioned three subtypes of osteosarcoma and the differences were reported as significant for all 15 factors in pairwise comparisons and the overall comparison. This may be due to the fact that the predominant factor associated to survival was metastasis vs. non-metastasis. Lee (39) reported that the event-free survival (EFS) rate of Korean children and adolescents with osteosarcoma at 5 years following diagnosis was 27.0 and $65.3 \%$ with and without metastasis, respectively. Kantar et al (40) reported that the 5-year EFS rates were 67 and $25 \%$ in patients with non-metastatic and metastatic disease, respectively. The present study demonstrated that the five-year survival rates in localized, regional and distant stages were $77.5,64.7$ and $31.1 \%$, respectively.

Two factors, grade and tumor size, had incomplete data and have been rarely analyzed in other studies. In the present study, tumors with grades of well and moderate differentiation had relatively good outcomes compared with those that were poorly differentiated and undifferentiated in the univariate analysis, possibly due to the fact that tumor differentiation reflects tumor malignancy. Larger tumors were reported to have relatively poor prognoses (41), which was confirmed in the present study, where tumors $>100 \mathrm{~mm}$ in size had relatively 
Table VI. Multivariate Cox regression analysis in patients <25 years of age with osteosarcoma between 1973 and 2012.

\begin{tabular}{|c|c|c|c|c|}
\hline \multirow[b]{2}{*}{ Variables } & \multicolumn{2}{|c|}{ Model 1} & \multicolumn{2}{|c|}{ Model 2} \\
\hline & HR $(95 \%$ CI $)$ & P-value & HR (95\%CI) & P-value \\
\hline Year of diagnosis & & $\mathrm{P}<0.001$ & & ${ }^{\text {ap }}<0.001$ \\
\hline 1973-1982 & Reference & & Reference & \\
\hline 1983-1992 & $0.649(0.500-0.841)$ & 0.001 & $0.657(0.529-0.816)$ & ${ }^{\mathrm{a}} \mathrm{P}<0.001$ \\
\hline 1993-2002 & $0.611(0.484-0.771)$ & $\mathrm{P}<0.001$ & $0.594(0.491-0.719)$ & ${ }^{\mathrm{a}} \mathrm{P}<0.001$ \\
\hline 2003-2012 & $0.528(0.418-0.666)$ & $\mathrm{P}<0.001$ & $0.507(0.419-0.613)$ & ${ }^{\mathrm{a}} \mathrm{P}<0.001$ \\
\hline Sex & & 0.042 & & ${ }^{\mathrm{a}} \mathrm{P}<0.001$ \\
\hline Male & Reference & & Reference & \\
\hline Female & $0.866(0.754-0.995)$ & 0.042 & $0.805(0.710-0.912)$ & ${ }^{\mathrm{a} P}<0.001$ \\
\hline Age at diagnosis (years) & & 0.042 & & 0.081 \\
\hline $0-4$ & Reference & & Reference & \\
\hline $5-9$ & $0.859(0.518-1.423)$ & 0.554 & $0.837(0.52-1.349)$ & 0.466 \\
\hline $10-14$ & $0.726(0.448-1.176)$ & 0.193 & $0.716(0.454-1.129)$ & 0.151 \\
\hline $15-19$ & $0.909(0.561-1.471)$ & 0.697 & $0.832(0.528-1.311)$ & 0.428 \\
\hline $20-24$ & $0.920(0.558-1.516)$ & 0.743 & $0.902(0.566-1.440)$ & 0.667 \\
\hline Race & & 0.452 & & \\
\hline Caucasian & Reference & & & \\
\hline African descent & $1.123(0.935-1.348)$ & 0.214 & & \\
\hline Other & $1.043(0.818-1.332)$ & 0.733 & & \\
\hline CHSDA region & & 0.003 & & ${ }^{\mathrm{a}} 0.035$ \\
\hline East & Reference & & Reference & \\
\hline Northern Plains & $1.372(1.101-1.711)$ & 0.005 & $1.190(0.978-1.448)$ & 0.082 \\
\hline Pacific Coast & $1.164(0.978-1.385)$ & 0.088 & $1.133(0.971-1.323)$ & 0.114 \\
\hline Southwest & $1.515(1.187-1.934)$ & 0.001 & $1.378(1.108-1.715)$ & ${ }^{\mathrm{a} 0} 0.004$ \\
\hline Rural or urban & & 0.71 & & \\
\hline Rural & Reference & & & \\
\hline Urban & $1.046(0.824-1.328)$ & 0.71 & & \\
\hline Stage & & $\mathrm{P}<0.001$ & & ${ }^{\mathrm{a}} \mathrm{P}<0.001$ \\
\hline Localized & Reference & & Reference & \\
\hline Regional & $1.612(1.360-1.911)$ & $\mathrm{P}<0.001$ & $1.585(1.360-1.848)$ & ${ }^{\mathrm{a}} \mathrm{P}<0.001$ \\
\hline Distant & $4.036(3.357-4.853)$ & $\mathrm{P}<0.001$ & $3.899(3.292-4.616)$ & ${ }^{\mathrm{a}} \mathrm{P}<0.001$ \\
\hline Laterality & & 0.944 & & \\
\hline Right & Reference & & & \\
\hline Left & $0.995(0.873-1.135)$ & 0.944 & & \\
\hline Histologic type ICD-O-3 & & $\mathrm{P}<0.001$ & & ${ }^{\text {a }} \mathrm{P}<0.001$ \\
\hline Osteosarcoma, NOS & Reference & & Reference & \\
\hline Chondroblastic & $0.821(0.669-1.008)$ & 0.060 & $0.869(0.721-1.046)$ & 0.137 \\
\hline Fibroblastic & $0.669(0.464-0.965)$ & 0.032 & $0.779(0.567-1.070)$ & 0.124 \\
\hline Telangiectatic & $0.770(0.538-1.102)$ & 0.154 & $0.782(0.553-1.107)$ & 0.166 \\
\hline Parosteal & $0.365(0.218-0.614)$ & $\mathrm{P}<0.001$ & $0.354(0.218-0.576)$ & ${ }^{\mathrm{a}} \mathrm{P}<0.001$ \\
\hline Primary site-labeled & & $\mathrm{P}<0.001$ & & ${ }^{\mathrm{a}} \mathrm{P}<0.001$ \\
\hline Upper limb & Reference & & Reference & \\
\hline Lower limb & $0.737(0.617-0.881)$ & 0.001 & $0.777(0.654-0.923)$ & a 0.004 \\
\hline Skull and mandible & $0.668(0.316-1.495)$ & 0.344 & $0.689(0.494-0.960)$ & ${ }^{\mathrm{a}} 0.028$ \\
\hline Vertebral and chest bones & $0.834(0.487-1.429)$ & 0.509 & $0.982(0.691-1.395)$ & 0.917 \\
\hline Pelvic bones & $1.625(1.157-2.281)$ & 0.005 & $1.612(1.210-2.147)$ & ${ }^{\mathrm{a}} 0.001$ \\
\hline Surgery & & $\mathrm{P}<0.001$ & & ${ }^{\mathrm{a}} \mathrm{P}<0.001$ \\
\hline Yes & Reference & & Reference & \\
\hline No & $1.726(1.434-2.077)$ & $\mathrm{P}<0.001$ & $1.645(1.391-1.946)$ & ${ }^{\mathrm{a}} \mathrm{P}<0.001$ \\
\hline
\end{tabular}


Table VI. Continued.

Model 1

Model 2

\begin{tabular}{|c|c|c|c|c|}
\hline \multirow[b]{2}{*}{ Variables } & & \\
\hline & $\mathrm{HR}(95 \% \mathrm{CI})$ & P-value & HR $(95 \% \mathrm{CI})$ & P-value \\
\hline Radiation & & $\mathrm{P}<0.001$ & & ${ }^{\mathrm{a}} \mathrm{P}<0.001$ \\
\hline Yes & Reference & & Reference & \\
\hline No & $0.600(0.461-0.781)$ & $\mathrm{P}<0.001$ & $0.548(0.442-0.679)$ & ${ }^{\mathrm{a}} \mathrm{P}<0.001$ \\
\hline
\end{tabular}


sion analysis. Model 1 excluded grade, tumor size and surgery type, which had incomplete data in the univariate analysis. Model 2 further excluded race, rural or urban, and laterality, which had no significant difference in the univariate analysis. HR, hazard ratio; CI, confidence interval; $n$, number; ICD, International Classification of Disease; NOS, not otherwise specified; CHSDA, Contract Health Service Delivery Areas.

poor outcomes compared with tumors $<50 \mathrm{~mm}$. Therefore, larger tumor sizes may reflect a more advanced stage of tumor development.

Miller et al (36) performed a histological analysis for patients with osteosarcoma of all ages, among which Paget diseases were reported to be more common in the elderly group ( $\geq 60$ years of age). However, in the present study only one case of Paget disease presented in the younger group $(<25$ years of age). In addition, small cell osteosarcoma was commonly associated with metastatic disease in the aforementioned study, in contrast to the present study. Nakajima et al (41) reviewed 72 cases with small cell osteosarcoma, concluding that this subtype of osteosarcoma is highly aggressive and less responsive to chemotherapy. The present study revealed two histologic types, parosteal and periosteal osteosarcoma, which were not associated with metastatic diseases. Parosteal osteosarcoma had relatively good survival outcomes compared with any other type of tumor, in accordance with the study of Mankin et al (42). Bacci et al (43) reported that fibroblastic and telangiectatic tumors had significantly higher 5-year overall survival rates, whereas chondroblastic and osteoblastic tumors had significantly lower 5-year overall survival rates. The effect of histologic type on metastasis and survival may be determined by biological characteristics of the tumors, however, further investigation is required.

The results of the present study indicated that the long bones of the four limbs were predilection sites for osteosarcoma. Lee (39) further reported that the most frequently affected site in children and adolescents was the distal femur $(52.3 \%)$. In the present study, extremity osteosarcoma had low metastasis and relatively good outcome, while axial skeletal osteosarcoma had the highest metastasis and worst outcome, confirming previous observations by Janinis et al (44), who reported that extremity tumors had a 2- and 3-year survival rate of 50 and $21 \%$, respectively, and axial skeletal tumors had a 2- and 3-year survival rate of 19 and 13\%, respectively. Meazza et al (45) studied 20 patients between the ages of 3 and 19 with axial skeletal osteosarcoma and reported a 5-year overall survival rate as low as 40\%. Among 129 cases of osteosarcomas, Akyuz et al (46) observed 6 cases of axial skeletal osteosarcomas, in which mortality occurred in 5 cases between three and sixteen months subsequent to diagnosis, indicating a poor prognosis. In the present study, the recorded sites were divided into 5 types to provide detailed information of tumor site and prognosis. According to the analysis, the tumor types ranked from best to worst survival outcome followed skull and mandible, lower limb, upper limb, vertebral and chest bones, and pelvic bones. An explanation for the aforementioned results is that axial skeletal osteosarcomas in vertebral, chest and pelvic bones may in close proximity to important organs, vessels or nerves, therefore, making complete resection difficult and possibly contributing to poor survival.

The type of surgery was analyzed in detail in the present study. Previous meta-analyses $(47,48)$ have reported that limb-salvage surgery confers better survival compared with amputation. Schrager et al (7) additionally reported the same trend in children and adolescents. Once modern prosthetics became available in the 1970s, there was an increase in limb-salvage surgeries performed, which corresponded to survival outcomes in comparison to amputation (7). It has been reported that limb-salvage surgery is the optimal choice in $85 \%$ of children patients with osteosarcoma $(49,50)$. Limb-salvage surgery may provide better outcomes compared with amputation, as amputation can cause psychological and functional impairment in young patients $(51,52)$. Furthermore, the present study compared survival outcomes among different types of surgery of the same stage or grade to exclude confounding factors and provide reliable results, as favorable outcomes may be due to mild disease rather than type of surgery. According to the order of best to worst survival outcome reported in the present study, surgery provided better outcomes compared with non-surgical treatment approaches, while excision provided better outcomes compared with amputation. Therefore, although removing the entire tumor may be the ideal choice for the treatment of osteosarcoma, excessive excision negatively affects body recovery. An interesting finding in the present study was that patients with metastatic diseases had a better survival rate when radical excision was chosen as a treatment option for osteosarcoma, possibly due to the fact that metastatic tumors tend to be larger and require to be thoroughly removed. Therefore, radical excision should be recommended for patients with metastatic diseases. Picci et al (53) identified inadequate margins in surgery as a risk factor for poor prognosis, confirming to an extent the results of the present study. 
The results of the present study initially indicated poor outcomes in patients who underwent radiation, however, further analysis indicated that the aforementioned result was not entirely valid. A total of $11.2 \%$ patients with metastatic diseases had undergone radiotherapy, whereas $3.9 \%$ of patients with non-metastatic diseases had undergone radiotherapy (data not shown). Therefore, a higher number of patients with metastatic diseases had received radiotherapy, indicating that the observed negative effect of radiotherapy was because patients with metastatic diseases had relatively poor overall prognosis.

The systematic analysis of the present study may provide useful information for guiding clinical work. Males patients between 10 and 19 years of age had a high incidence rate of osteosarcoma, suggesting the requirement for an early screening of this aforementioned high-risk population for osteosarcoma. Chest and pelvic bones were at high risk of metastasis, therefore, metastatic lesions should be checked among high-risk patients. Year of diagnosis, sex, CHSDA region, stage, histologic type, tumor site, surgery and radiation were demonstrated in the present study to be independent risk factors in the multivariate Cox regression analysis. In order to improve survival rate, local excision can be used in the majority of patients with osteosarcoma, and radical excision is suggested for patients with metastatic diseases.

However, the present study presents certain limitations. Firstly, information regarding chemotherapy treatment is not available in the SEER database, therefore extracting information associated with the type of drugs used for chemotherapy treatments was not possible. Secondly, no detailed record of the type of surgery was available, therefore, determining for example if patients had undergone joint replacement was not possible. Thirdly, the present study was retrospective rather than a randomized controlled trial, therefore, whether to perform a limb-salvage surgery or an amputation depended on the doctors' suggestion and the patient's requirement rather than random assignment. Finally, there were no therapy records of biologic markers and no records of tumor recurrence. Despite the aforementioned limitations, the present study incorporated a relatively large number of osteosarcoma cases from the SEER database, increasing the accuracy of present study's results.

\section{Acknowledgements}

The authors thank the National Natural Science Foundation of China (Beijing, China). The authors also thank the National Cancer Institute (Bethesda, USA), who provided access to the public SEER database.

\section{Funding}

The present study was supported by the National Natural Science Foundation of China (grant, no., 81672154; Beijing, China).

\section{Availability of data and materials}

The datasets generated and/or analyzed during the current study are available in the Surveillance, Epidemiology, and End Results (SEER) repository, https://seer.cancer.gov/.

\section{Authors' contributions}

$\mathrm{ZN}$ acquired data, analyzed data and wrote the manuscript. HP acquired data, designed the study, revised the manuscript and gave final approval of the version to be published. All authors read and approved the final version of the manuscript.

\section{Ethics approval and consent to participate}

Ethics approval and consent to participate are not needed as this study is based on already existing data from the National Cancer Institute. The present study was approved by the National Cancer Institute.

\section{Patient's consent for publication}

Not applicable.

\section{Competing interests}

The authors declare that they have no competing interests.

\section{References}

1. Damron TA, Ward WG and Stewart A: Osteosarcoma, chondrosarcoma, and ewing's sarcoma: National cancer data base report. Clin Orthop Relat Res 459: 40-47, 2007.

2. Mirabello L, Troisi RJ and Savage SA: Osteosarcoma incidence and survival rates from 1973 to 2004 : Data from the surveillance, epidemiology, and end results program. Cancer 115: 1531-1543, 2009.

3. Anfinsen KP, Devesa SS, Bray F, Troisi R, Jonasdottir TJ, Bruland OS and Grotmol T: Age-period-cohort analysis of primary bone cancer incidence rates in the United States (1976-2005). Cancer Epidemiol Biomarkers Prev 20: 1770-1777, 2011.

4. Duong LM and Richardson LC: Descriptive epidemiology of malignant primary osteosarcoma using population-based registries, United States, 1999-2008. J Registry Manag 40: 59-64, 2013.

5. Tsuda Y, Ogura K, Shinoda Y, Kobayashi H, Tanaka S and Kawai A: The outcomes and prognostic factors in patients with osteosarcoma according to age: A Japanese nationwide study with focusing on the age differences. BMC Cancer 18: 614, 2018.

6. Wang W, Yang J, Wang Y, Wang D, Han G, Jia J, Xu M and Bi W: Survival and prognostic factors in Chinese patients with osteosarcoma: 13-year experience in 365 patients treated at a single institution. Pathol Res Pract 213: 119-125, 2017.

7. Schrager J, Patzer RE, Mink PJ, Ward KC and Goodman M: Survival outcomes of pediatric osteosarcoma and Ewing's sarcoma: A comparison of surgery type within the SEER database, 1988-2007. J Registry Manag 38: 153-161, 2011.

8. Perkins SM, Shinohara ET, DeWees T and Frangoul H: Outcome for children with metastatic solid tumors over the last four decades. PLoS One 9: e100396, 2014.

9. Gatta G, Capocaccia R, Coleman MP, Ries LA and Berrino F: Childhood cancer survival in europe and the united states. Cancer 95: 1767-1772, 2002.

10. Novakovic B: U.S. childhood cancer survival, 1973-1987. Med Pediatr Oncol 23: 480-486, 1994.

11. Duchman KR, Gao Y and Miller BJ: Prognostic factors for survival in patients with high-grade osteosarcoma using the surveillance, epidemiology, and end results (SEER) program database. Cancer Epidemiol 39: 593-599, 2015.

12. Foster L, Dall GF, Reid R, Wallace WH and Porter DE: Twentieth-century survival from osteosarcoma in childhood. Trends from 1933 to 2004. J Bone Joint Surg Br 89: 1234-1238, 2007.

13. Longhi A, Errani C, De Paolis M, Mercuri M and Bacci G: Primary bone osteosarcoma in the pediatric age: State of the art. Cancer Treat Rev 32: 423-436, 2006. 
14. Duffaud F, Digue L, Mercier C, Dales JP, Baciuchka-Palmaro M, Volot F, Thomas P and Favre R: Recurrences following primary osteosarcoma in adolescents and adults previously treated with chemotherapy. Eur J Cancer 39: 2050-2057, 2003.

15. Kawaguchi K, Igarashi K, Li S, Han Q, Tan Y, Miyake K, Kiyuna T, Miyake M, Murakami T, Chmielowski B, et al: Recombinant methioninase (rMETase) is an effective therapeutic for BRAF-V600E-negative as well as-positive melanoma in patient-derived orthotopic xenograft (PDOX) mouse models. Oncotarget 9: 915-923, 2018.

16. Murakami T, Igarashi K, Kawaguchi K, Kiyuna T, Zhang Y, Zhao M, Hiroshima Y, Nelson SD, Dry SM, Li Y, et al: Tumor-targeting Salmonella typhimurium A1-R regresses an osteosarcoma in a patient-derived xenograft model resistant to a molecular-targeting drug. Oncotarget 8: 8035-8042, 2017.

17. Igarashi K, Kawaguchi K, Murakami T, Kiyuna T, Miyake K, Nelson SD, Dry SM, Li Y, Yanagawa J, Russell TA, et al: Intra-arterial administration of tumor-targeting Salmonella typhimurium A1-R regresses a cisplatin-resistant relapsed osteosarcoma in a patient-derived orthotopic xenograft (PDOX) mouse model. Cell Cycle 16: 1164-1170, 2017.

18. Igarashi K, Murakami T, Kawaguchi K, Kiyuna T, Miyake K, Zhang Y, Nelson SD, Dry SM, Li Y, Yanagawa J, et al: A patient-derived orthotopic xenograft (PDOX) mouse model of a cisplatinum-resistant osteosarcoma lung metastasis that was sensitive to temozolomide and trabectedin: Implications for precision oncology. Oncotarget 8: 62111-62119, 2017.

19. Igarashi K, Kawaguchi K, Kiyuna T, Miyake K, Miyake M, Li Y, Nelson SD, Dry SM, Singh AS, Elliott IA, et al: Temozolomide combined with irinotecan regresses a cisplatinum-resistant relapsed osteosarcoma in a patient-derived orthotopic xenograft (PDOX) precision-oncology mouse model. Oncotarget 9: 7774-7781, 2017.

20. Mirabello L, Pfeiffer R, Murphy G, Daw NC, Patino-Garcia A, Troisi RJ, Hoover RN, Douglass C, Schuz J, Craft AW and Savage SA: Height at diagnosis and birth-weight as risk factors for osteosarcoma. Cancer Causes Control 22: 899-908, 2011.

21. Arora RS, Alston RD, Eden TO, Geraci M and Birch JM: The contrasting age-incidence patterns of bone tumours in teenagers and young adults: Implications for aetiology. Int J Cancer 131: $1678-1685,2012$.

22. Greil H and Kahl H: Assessment of developmental age: Cross-sectional analysis of secondary sexual characteristics. Anthropol Anz 63: 63-75, 2005.

23. Longhi A, Pasini A, Cicognani A, Baronio F, Pellacani A, Baldini N and Bacci G: Height as a risk factor for osteosarcoma. J Pediatr Hematol Oncol 27: 314-318, 2005.

24. Gelberg KH, Fitzgerald EF, Hwang S and Dubrow R: Growth and development and other risk factors for osteosarcoma in children and young adults. Int J Epidemiol 26: 272-278, 1997.

25. Endicott AA, Morimoto LM, Kline CN, Wiemels JL, Metayer C and Walsh KM: Perinatal factors associated with clinical presentation of osteosarcoma in children and adolescents. Pediatr Blood Cancer 64, 2017.

26. Homa DM, Sowers MR and Schwartz AG: Incidence and survival rates of children and young adults with osteogenic sarcoma. Cancer 67: 2219-2223, 1991.

27. Petrilli AS, Gentil FC, Epelman S, Lopes LF, Bianchi A, Lopes A Figueiredo MT, Marques E, De Bellis N and Consentino E: Increased survival, limb preservation, and prognostic factors for osteosarcoma. Cancer 68: 733-737, 1991.

28. Smeland S, Muller C, Alvegard TA, Wiklund T, Wiebe T, Bjork O, Stenwig AE, Willen H,Holmstrom T, Folleras G, et al: Scandinavian Sarcoma Group Osteosarcoma Study SSG VIII: prognostic factors for outcome and the role of replacement salvage chemotherapy for poor histological responders. Eur J Cancer 39: 488-494, 2003.

29. Bielack SS, Kempf-Bielack B, Delling G, Exner GU, Flege S, Helmke K, Kotz R, Salzer-Kuntschik M, Werner M, Winkelmann W, et al: Prognostic factors in high-grade osteosarcoma of the extremities or trunk: an analysis of 1,702 patients treated on neoadjuvant cooperative osteosarcoma study group protocols. J Clin Oncol 20: 776-790, 2002.

30. Saeter G, Elomaa I, Wahlqvist Y, Alvegard TA, Wiebe T, Monge O, Forrestier E and Solheim OP: Prognostic factors in bone sarcomas. Acta Orthop Scand Suppl 273: 156-160, 1997.

31. Guillon MA,Mary PM,Brugiere L, Marec-Berard P,Pacquement HD Schmitt C, Guinebretiere JM and Tabone MD: Clinical characteristics and prognosis of osteosarcoma in young children: A retrospective series of 15 cases. BMC Cancer 11: 407, 2011.

32. Worch J, Matthay KK, Neuhaus J, Goldsby R and DuBois SG: Osteosarcoma in children 5 years of age or younger at initial diagnosis. Pediatr Blood Cancer 55: 285-289, 2010.
33. Sugalski AJ, Jiwani A, Ketchum NS, Cornell J, Williams R, Heim-Hall J, Hung JY and Langevin AM: Characterization of localized osteosarcoma of the extremity in children, adolescents, and young adults from a single institution in south texas. J Pediatr Hematol Oncol 36: e353-e358, 2014

34. Hagleitner MM, Hoogerbrugge PM, van der Graaf WT, Flucke U, Schreuder HW and te Loo DM: Age as prognostic factor in patients with osteosarcoma. Bone 49: 1173-1177, 2011.

35. Neel MD, Wilkins RM, Rao BN and Kelly CM: Early multicenter experience with a noninvasive expandable prosthesis. Clin Orthop Relat Res: 72-81, 2003.

36. Miller BJ, Cram P, Lynch CF and Buckwalter JA: Risk factors for metastatic disease at presentation with osteosarcoma: An analysis of the SEER database. J Bone Joint Surg Am 95: e89, 2013.

37. Jawad MU, Cheung MC, Clarke J, Koniaris LG and Scully SP: Osteosarcoma: Improvement in survival limited to high-grade patients only. J Cancer Res Clin Oncol 137: 597-607, 2011

38. Clark JC, Dass CR and Choong PF: A review of clinical and molecular prognostic factors in osteosarcoma. J Cancer Res Clin Oncol 134: 281-297, 2008.

39. Lee JA: Osteosarcoma in Korean children and adolescents. Korean J Pediatr 58: 123-128, 2015.

40. Kantar M, Cetingul N, Azarsiz S, Kansoy S, Sabah D, Memis A, Basdemir G and Burak Z: Treatment results of osteosarcoma of the extremity in children and adolescents at ege university hospital. Pediatr Hematol Oncol 19: 475-482, 2002.

41. Nakajima H, Sim FH, Bond JR and Unni KK: Small cell osteosarcoma of bone. Review of 72 cases. Cancer 79: 2095-2106, 1997.

42. Mankin HJ, Hornicek FJ, Rosenberg AE, Harmon DC and Gebhardt MC: Survival data for 648 patients with osteosarcoma treated at one institution. Clin Orthop Relat Res: 286-291, 2004.

43. Bacci G, Bertoni F, Longhi A, Ferrari S, Forni C, Biagini R, Bacchini P, Donati D, Manfrini M, Bernini G and Lari S: Neoadjuvant chemotherapy for high-grade central osteosarcoma of the extremity. Histologic response to preoperative chemotherapy correlates with histologic subtype of the tumor. Cancer 97: 3068-3075, 2003

44. Janinis J, McTiernan A, Driver D, Mitchell C, Cassoni AM, Pringle J, Kilby A and Whelan JS and London Bone and Soft Tissue Tumour Service: A pilot study of short-course intensive multiagent chemotherapy in metastatic and axial skeletal osteosarcoma. Ann Oncol 13: 1935-1944, 2002.

45. Meazza C, Luksch R, Daolio P, Podda M, Luzzati A, Gronchi A, Parafioriti A, Gandola L, Collini P, Ferrari A, et al: Axial skeletal osteosarcoma: A 25-year monoinstitutional experience in children and adolescents. Med Oncol 31: 875, 2014.

46. Akyuz C, Ilhan I, Kutluk T and Buyukpamukcu M: Primary osteosarcoma presenting in axial bones in childhood. Turk J Pediatr 37: 375-381, 1995

47. Han G, Bi WZ, Xu M, Jia JP and Wang Y: Amputation versus limb-salvage surgery in patients with osteosarcoma: A meta-analysis. World J Surg 40: 2016-2027, 2016.

48. Li X, Zhang Y, Wan S, Li H, Li D, Xia J, Yuan Z, Ren M, Yu S, Li S, et al: A comparative study between limb-salvage and amputation for treating osteosarcoma. J Bone Oncol 5: 15-21, 2016.

49. Grimer RJ: Surgical options for children with osteosarcoma. Lancet Oncol 6: 85-92, 2005.

50. Wafa $\mathrm{H}$ and Grimer RJ: Surgical options and outcomes in bone sarcoma. Expert Rev Anticancer Ther 6: 239-248, 2006.

51. Postma A, Kingma A, De Ruiter JH, Schraffordt Koops H, Veth RP, Goeken LN and Kamps WA: Quality of life in bone tumor patients comparing limb salvage and amputation of the lower extremity. J Surg Oncol 51: 47-51, 1992.

52. Aksnes LH, Bauer HC, Jebsen NL, Folleras G, Allert C, Haugen GS and Hall KS: Limb-sparing surgery preserves more function than amputation: A Scandinavian sarcoma group study of 118 patients. J Bone Joint Surg Br 90: 786-794, 2008.

53. Picci P, Sangiorgi L, Bahamonde L, Aluigi P, Bibiloni J,Zavatta M, Mercuri M, Briccoli A and Campanacci M: Risk factors for local recurrences after limb-salvage surgery for high-grade osteosarcoma of the extremities. Ann Oncol 8: 899-903, 1997.

This work is licensed under a Creative Commons Attribution-NonCommercial-NoDerivatives 4.0 International (CC BY-NC-ND 4.0) License. 